\title{
Sociedad civil y masonería en la ciudad de Zaca- tecas (1959-1977)
}

\section{Civil society and freemasonry in the city of Zacatecas (1959-1977)}

César Eduardo Gutiérrez Rojas

Universidad Autónoma de Zacatecas, México eduguti_27@hotmail.com

Recepción: 11 de abril de 2020/Aceptación: 17 de abril de 2020

doi: https://doi.org/10.15517/rehmlac.v12i1-2.41382

\section{Palabras clave}

Sociedad civil; masonería; capital social; logia.

\section{Keywords}

Civil Society; Freemasonry; Social Capital; Lodge.

\section{Resumen}

El concepto sociedad civil fue calificado prodemocrático y encasillado a las ONG y a las OSC, condicionando su interpretación. Situación similar fue el vínculo conceptual con los grupos políticos disidentes del gobierno mexicano en las décadas de 1950 a 1970, consecuencia del contexto autoritario-corporativo y las restricciones político-partidistas, provocando el uso de máscaras civiles para realizar sus agendas. Ambas posturas nulificaron otras posibilidades de análisis, radicando en ello la importancia de nuestra investigación, pues se conformó un concepto a partir de debates ideológicos, identificando en la asociación masónica de la ciudad de Zacatecas una propuesta de sociedad civil a desarrollar.

\section{Abstract}

The concept of civil society was classified as pro-democratic and pigeonholed for NGO's and OSC's, conditioning its interpretation. A similar situation was the conceptual link with the dissident political groups of the Mexican government from 1950 to 1970 , as a consequence of the authoritarian-corporate context and the political-partisan restrictions, causing the use of civilian masks to carry out their agendas. Both positions nullified other possibilities of analysis, which is the reason for the importance of our research, thus a concept stemmed from ideological debates, identifying in the Masonic association of the city of Zacatecas a proposal to develop civil society. 


\section{Introducción}

El concepto sociedad civil ha estado presente en la historia moderna occidental, primero para diferenciar la esfera pública de la privada de acuerdo con las actividades que se realizan en cada una: la pública relacionada a la política, sus instituciones, el ejercicio de poder; mientras lo privado es respecto de lo civil, las personas, la familia, el mercado, las asociaciones.

El término sociedad civil se retomó en México a finales del siglo XX para uso de la Ciencia Política y la Sociología, dando cuenta de organizaciones ajenas a la búsqueda del ejercicio del poder político o del lucro en el mercado, ejemplificándolo mediante acciones como los rescates de damnificados del terremoto de 1985 en la capital del país, las manifestaciones a favor de los refugiados políticos centroamericanos y la conformación de organizaciones que incursionaron en las disputas electorales vigilando el proceso, como Convergencia de Organizaciones Civiles para la Democracia y Alianza Cívica².

Con la interpretación de la sociedad civil a finales del siglo XX para explicar la participación pública, mecanismos de persuasión e implementación de derechos civiles y políticos por medio de asociaciones ambientalistas, feministas y de derechos humanos. La sociedad civil fue encasillada en las organizaciones no gubernamentales (ONG) y las organizaciones de la sociedad civil (OSC) $)^{2}$, excluyendo otras formas de organización y condicionando el concepto.

\section{Antecedentes, problemática y justificación}

Alberto Olvera Rivera expone la sociedad civil como una colectividad prodemocrática que se constituyó durante la crisis del régimen autoritario, definiéndola así por su participación pública en el sufragio y más allá de este, clarificando la autonomía de la sociedad y su quehacer dentro del sistema político mexicano33. Su análisis refutó la correspondencia del concepto con las organizaciones políticas disidentes identificadas a partir de la segunda mitad del siglo XX, debido a que sus fines no eran civiles, además su formación no fue voluntaria, pues fueron parte del corporativismo. La vinculación de la sociedad civil con las disidencias políticas negó otras relaciones entre personas y formas de manifestación ciudadana, tanto en la esfera privada como en la pública que podemos resignificar, siendo el motivo y objetivo de este texto: identificar asociaciones civiles que no corresponden al modelo prodemocrático ni a las disidencias políticas en un caso local, la ciudad de Zacatecas entre las décadas de 1950 a 1970, proponiendo la masonería como ejemplo de lo referido.

La temporalidad establecida corresponde al autoritarismo mexicano, concepto acuñado por Juan J. Linz para describir sistemas políticos no totalitarios, pero sí con restricciones en

1 María Fernanda Somuano, "Las organizaciones civiles: formación y cambio", en Los grandes problemas de México. Instituciones y procesos políticos, coords. Soledad Loaeza y Jean-François Prud'homme (México DF: El Colegio de México, 2010), tomo XIV, 198.

2 Alberto J. Olvera Rivera, "Democracia y sociedad civil en México: lecciones y tareas", Comercio exterior 52, no. 5 (mayo 2002): 400-402.

3 Olvera Rivera, coord., La sociedad civil: de la teoría a la realidad (México DF: El Colegio de México, 1999), 11-17 y "De la sociedad civil política y los límites y posibilidades de la política de la sociedad civil: el caso de Alianza Cívica y la transición democrática en México", en Los grandes problemas de México. Movimientos sociales, coords. Ilán Bizberg y Francisco Zapata (México DF: El Colegio de México, 2010), tomo VI, 185. 
la competencia política y en la organización social4. Durante esa etapa histórica el gobierno mexicano fortaleció su dominación cohesionando o coaccionando a los sectores populares bajo un ideal nacionalista, ejerciendo violencia física o simbólica sobre toda acción disentida.

A finales de la década de 1950, el sistema político autoritario se organizó bajo un pacto corporativo que cimentó la relación con diferentes sectores de la sociedad, el gobierno creó asociaciones para movilizar o desmovilizar según conveniencia`; además de identificar nuevas dirigencias para cooptarlas en las corporaciones oficiales como la Confederación de Trabajadores de México (CTM), Confederación Nacional Campesina (CNG) y Confederación Nacional de Organizaciones Populares (CNOP) ${ }^{6}$. El enfoque del corporativismo-autoritario mexicano da una referencia endeble respecto a la construcción de grupos de la sociedad civil autónomos del régimen político autoritario.

Rubén Aguilar Valenzuela argumenta que en las primeras décadas del siglo XX el gobierno posrevolucionario era capaz de cubrir todos los campos haciendo innecesario el proyecto de desarrollo de cualquier organismo de la sociedad civil, tomando partido en las diferentes organizaciones ciudadanas ya fueran sindicalistas, urbanistas, cooperativistas, entre otras. Aguilar Valenzuela refiere a un corporativismo que se enfocó en absorber a las organizaciones populares. Los posibles entes sociales autónomos, constituidos por voluntad individual y no por intervención gubernamental, los identifica en el sector empresarial, la Iglesia católica y las clases medias, las cuales se encontraban en proceso y propagación, consecuencia del desarrollo estabilizador y la urbanización?

Ambos enfoques presentan una incipiente y débil sociedad civil porque se busca en su modelo prodemocrático, irrumpiendo la intromisión estatal en la vida asociativa. En un estudio histórico, retomar el concepto "prodemocrático" dentro de una delimitación temporal entre los decenios 1950 y 1970 resulta anacrónico, pues el régimen y el sistema político ${ }^{8}$ señalaron los disentimientos, lo cual no quiere decir que no se conformaran organizaciones o asociaciones voluntarias, ubicadas en la periferia del gobierno y sin el objetivo de democratizar la vida pública. Pensar la sociedad civil como disidencias, nos llevaría a un análisis del sistema corporativo a través del "pacto de dominación”, una depreciación de otras agrupaciones, obteniendo una visión sesgada de la sociedad, de los diferentes objetivos y entenderes que orientaron la reunión de personas en la esfera privada y dependiendo de sus posibilidades, partícipes de lo público sin buscar el poder político.

4 Jesús Silva-Herzog Márquez, El antiguo régimen y la transición en México (México DF: Planeta/Joaquín Mortiz, 1999$), 21$.

5 Diana Margarita Favela Gavia, Protesta y reforma en México. Interacción entre Estado y sociedad 1946-1997 (México DF: UNAM/Plaza y Valdés, 2006), 5.

6 Bizberg, "Una democracia vacía. Sociedad civil, movimientos sociales y democracia", en Los grandes problemas de México, tomo VI, 26-29.

7 Rubén Aguilar Valenzuela, "Las organizaciones de la sociedad civil en México: su evolución y principales retos" (tesis de doctorado en ciencias sociales, Universidad Iberoamericana, 2006), 118-119.

8 Para este trabajo se entiende por Régimen político a las instituciones fundamentadas jurídicamente, mientras que por Sistema político se concibe a las relación informales entre los actores políticos y los sociales, como es el caso del corporativismo, la subordinación, el intercambio de intereses entre gobernados, gobernantes y la reproducción de acciones o ideales afines al régimen político. Conceptos tomados de Luis Medina Peña, La invención del sistema político mexicano. Forma de gobierno y de gobernabilidad en México en el siglo XIX (México DF: Fondo de Cultura Económica, 2004), 11-25.

9 Viviane Brachet-Márquez, El pacto de dominación. Estado, clase y reforma social en México (1910-1995) (México DF: El Colegio de México, 1996), 59-64. 
En el caso de la ciudad de Zacatecas (capital del estado), entre los años 1959 y 1977, el gobierno estatal continuó con la línea implantada por el gobierno federal al cooptar la vida social por medio de organizaciones civiles vinculadas con las corporaciones nacionales; ejemplo de ello fue la relación de subordinación de la Federación de Organizaciones Populares de Zacatecas $^{10}$, con la CNOP. Dentro de la temporalidad referida y acorde con aconteceres nacionales, la ciudad de Zacatecas se caracterizó por ser escenario de manifestaciones políticas disidentes, las cuales debido a las restricciones del sistema autoritario usaron el estandarte civil para exponer sus quehaceres divergentes de los organismos corporativos ${ }^{11}$.

Ese marco contextual estimula el estudio de asociaciones, grupos y sociabilidades autónomas del Estado, del mercado y de la disidencia política, constituidas con objetivos ciudadanos y voluntad propia. Es en este argumento donde radica la importancia del texto, pues se propone observar una sociedad civil conformada por asociaciones voluntarias, autónomas, ajenas a intereses gubernamentales y económicos, las cuales, debido a sus quehaceres, no corresponden al modelo prodemocrático ni a las manifestaciones reivindicativas, pues no buscaban garantías corporativas ni ser contrapeso del gobierno y sus corporaciones.

\section{Metodología, objetivo y propuesta de la investigación}

Las asociaciones, sociabilidades o los clubes, ya sean de lectura, recreativos, deportivos, de servicio, filantrópicos, religiosos o cívicos, entre otros, son parte del mundo de la sociedad civil. Es menester aclarar que, debido a su permanencia, identificación y trascendencia, es más factible estudiar los grupos de mayor formalidad, siendo uno de los motivos por los cuales nos enfocamos en la masonería zacatecana, específicamente en la logia Úrsulo A. García por su producción documental.

Las fuentes consultadas fueron periódicos, folletos e impresos de la ciudad de Zacatecas distribuidos entre las décadas de 1940 y 1970, además de las actas de sesión de la logia Úrsulo A. García, patrimonio de la Gran Logia del Estado de Zacatecas "Jesús González Ortega”, con la finalidad de conocer las discusiones de los masones sobre cuestiones de interés común, así como sus quehaceres ciudadanos en el espacio público.

Para este estudio se entiende por sociedad civil al total de reuniones, sociabilidades, asociaciones formales e informales de ciudadanos que voluntariamente intercambian intereses propios, construyen públicos autónomos de la economía y la política, pero interactúan con ambas esferas por medio de opiniones o acciones que revelan los objetivos civiles de su sociedad. La identificación de la asociación masónica como objeto de estudio es debido a que se constituyen mediante individualidades, que con intereses similares, códigos culturales semejantes, intercambio de objetivos personales, se reúnen, haciéndose presentes en el espacio común sin perder sus fines ciudadanos y su autonomía frente al Estado.

\footnotetext{
$10 \quad$ Provincia, mayo 4 de 1957, Zacatecas, 1 y 7.

11 Manuel García Hernández, "Los partidos políticos de izquierda en Zacatecas en la década de los ochenta" (tesis de maestría en ciencia política, Universidad Autónoma de Zacatecas, 1989), 213-225.
} 
El modelo de sociedad civil se encuentra condicionado por el proceso histórico social, el resultado societario puede ser moderno al contar con elementos como la constitución de un mercado autónomo, un Estado de derecho y la libertad de asociación; así como también tradicional al tener como base asociativa relaciones basadas en la imposición y no en la voluntad ${ }^{12}$, o híbrido al presentar una combinación de componentes modernos, como la libre asociación y vínculos corporativos mezclados con relaciones entre individuos ${ }^{13}$. En el caso italiano, donde persisten fuertes usanzas comunitarias, se le denominó a este fenómeno capital social ${ }^{14}$, por tanto, la sociedad civil en su modelo híbrido, es la formación de capital social, debido a que las organizaciones conformadas por individualidades buscan implantar sus valores cívicos y asociativos en las corporaciones tradicionales.

El capital social se conforma de tres elementos presentes en la sociedad: asociativismo, generación de relaciones de confianza y propagación de una cultura cívica y cohesión social ${ }^{15}$. Elementos que para nuestro estudio son fomentados por la asociación masónica, contribuyéndonos a identificar su finalidad pública al buscar establecer sus valores como prescripciones sociales, que dependiendo de sus disertaciones, fueron tomadas o adecuadas por los gobiernos para fortalecer su dominación.

El objetivo de esta investigación es analizar la masonería y sus asociados como actores de la sociedad civil, que mediante la opinión y quehaceres en el espacio público manifestaron su ideal societario, cuyo objetivo contempló civilizar, moralizar y secularizar el entorno público y privado. Sus esfuerzos se enfocaron en la educación laica, entendiéndola como una forma de ciudadanizar y de combinar la conciencia individual con solidaridades tradicionales en beneficio de la sociedad, dando pie a la virtud pública y la construcción de su ciudadano ideal. Por tanto, planteamos la conformación de la asociación masónica como parte de una sociedad civil híbrida al constituirse mezclando ideales modernos con tradicionales, de manera que su finalidad no era democratizar la vida pública, pero sí ser partícipes de la esfera común con el objetivo de formar capital social, instaurar valores culturales, prescripciones sociales y establecerse como el sector hegemónico ciudadano.

\section{Masonería zacatecana como sociedad civil}

La masonería se considera parte del mundo de la sociedad civil al ser una asociación formal y voluntaria para argumentar inquietudes propias, conformar sociabilidades, agrupaciones, núcleos de interacción autónomos del mercado y del Estado, coexistiendo con ambas esferas a través de discusiones y acciones públicas que muestran los fines civiles de la logia. El análisis de la institución masónica aporta para el estudio de la sociedad civil debido a su modelo de interacción entre sus agremiados, donde el diálogo, el disentir y cuestionar acciones en el espacio común, se realiza con mayor libertad al encontrarse en un espacio seguro como la logia.

\footnotetext{
12 Olvera, "Democracia", 398-408.

13 Víctor Manuel Andrade Guevara, "Xalapa: la formación de la esfera pública en el siglo XIX”, Ulúa. Revista de Historia, sociedad y cultura 26 (julio-diciembre 2015): 211-255.

14 José Antonio Aguilar Rivera, En pos de la quimera. Reflexiones sobre el experimento constitucional atlántico (México DF: Fondo de Cultura Económica, 2000), 32-33.

15 Felipe de la Hevia Jara y Olvera Rivera, "Capital social en el estado de Veracruz", en Violencia, inseguridad y justicia en Veracruz, ed. Olvera Rivera (Xalapa: Universidad Veracruzana, 2015), 165-213.
} 
Dentro de la temporalidad establecida de 1959 a 1977 y en el espacio geográfico definido, se identificaron organizaciones formales parte de la sociedad civil de la ciudad de Zacatecas, cuya principal característica es la asociación. Sin embargo, considerando la sociedad civil como esfera de interacción de personas que en el uso de su voluntad deciden ser parte de una organización ciudadana sin fines de lucro o políticos, da pie a problematizar cuáles tienen las características aludidas, pues algunas asociaciones encubrieron objetivos políticos disfrazados de fines civiles.

La masonería a diferencia de otras organizaciones como los Clubes Rotarios o Leones, son asociaciones donde se discute sobre temas personales y también de interés común, consecuencia de realizar sus sesiones en espacios cerrados y exclusivos para los socios. Los masones de la segunda mitad del siglo XX en la ciudad de Zacatecas eran burócratas y comerciantes, sus opiniones dentro de la logia cuestionaban las formas tradicionales de organización en la ciudad de Zacatecas, pero no rompían de tajo con ellas, creían en la secularización de la sociedad y bajo esa convicción actuaban mediante hechos e impresos que se distribuían entre sus círculos de sociabilidad, formando esferas públicas. "Las discusiones llevadas a cabo en sus logias (salones de reunión) pasaron a ser de opiniones a la opinión” ${ }^{16}$.

La masonería de la ciudad de Zacatecas durante la primera mitad del siglo XX no fue constante, su mayor problema fue la falta de quorum para realizar sus reuniones, inconveniente que se venía arrastrando desde finales del siglo XIX. La primera logia instalada en la ciudad de Zacatecas en el siglo pasado fue la Francisco García Salinas núm. 30, puesta en función en 1917 por Ricardo Villalpando, delegado de la Gran Logia del Valle de México. La asociación tuvo actividad durante 28 años, siendo clausurada en 1945 por insuficiencia de miembros que la sostuvieran económicamente. Los años con mayor dinamismo masónico entre las décadas de 1910 y 1950 en la ciudad de Zacatecas fueron los de 1920, instalándose una logia capitular con el nombre Lorenzo T. Villaseñor a la cual solo asistieron los grados consecutivos de los tres primeros del Rito Escocés Antiguo y Aceptado (REAyA) indicando la actividad de un número significativo de maestros masones del $4^{\circ}$ al $14^{\circ}$; sin embargo, el cierre de este taller en 1933, fue la antesala de la clausura de la logia Francisco García Salinas en $1945^{17}$, situación que provocó una migración de masones zacatecanos hacia las organizaciones de la ciudad de Aguascalientes, especialmente la logia Benito Juárez ${ }^{18}$.

El último registro de actividades masónicas que se tiene en la primera mitad del siglo XX en la ciudad de Zacatecas data del 11 de julio de 1948, con la instauración de la logia Jesús González Ortega; no obstante, no se vuelve a tener testimonio del quehacer masónico en la ciudad, hasta la instalación de la logia Úrsulo A. García núm. 284, auspiciada por la Gran Logia del Valle de México y con siete socios activos ${ }^{19}$, siendo madre logia de la masonería actual en la ciudad,

\footnotetext{
16 Hevia Jara y Olvera Rivera, "Capital social”, 159.

17 Ángela Dianalthé Flores, “La masonería en el Estado de Zacatecas”, Digesto documental de Zacatecas IV, no. 7 (2006): 123-126.

18 Archivo Histórico Municipal de Zacatecas (AHMZ), Col. Dr. José Enciso Contreras, Serie: Masonería. Gran Logia Jesús González Ortega, 30 de abril 1964, "Datos relativos a la carrera masónica del H. Tomás Lorck Frutos".

19 En la formación de las logias Benito Juárez de Fresnillo y Úrsulo A. García de Zacatecas, Tomás Lorck Frutos fue de los principales masones que fomentó su conformación, quien también es considerado el vínculo entre la masonería decimonónica zacatecana y la del siglo XX. Vicente Sánchez Murillo, "Formación de la Muy Respetable Gran Logia del Estado de Zacatecas Jesús González Ortega", octubre 2011, https://issuu.com/edual21/docs/historia_de_la_masoner_a_en_zacatecas
} 
pues de ella surgieron los maestros masones fundadores de los talleres Salvador Allende G. núm. 117, erigida en 1975; Benito Juárez núm. 269, fundada en 1980, y Antonio Rosales Flores núm. 161 de $1985^{20}$.

\section{La logia Úrsulo A. García: espacio de diálogo, opinión y discusión}

Las actividades profanas de masones fueron diversas y salvo algunas excepciones, no relacionadas directamente al ejercicio del poder político como se suele suponer. La trascendencia del análisis de la organización masónica como parte de la sociedad civil zacatecana es su pertinencia para cuestionar el monopolio de la publicidad, la crítica y la organización social por parte del Estado mexicano posrevolucionario, por medio de sus organismos corporativos.

Las acciones de los integrantes de la logia de la ciudad de Zacatecas, ya fuera en su investidura de masones o de ciudadanos, tenía un fin secular que motivaba su participación mediante acciones concretas o manifestando su opinión. En las tenidas los masones encontraban el espacio de libertad para exteriorizar sus inquietudes civiles sobre la cosa pública, cada masón, ciudadano o persona asistente a la Úrsulo A. García, en pleno uso de su libertad individual, formulaba opiniones basadas en decisiones propias y racionales. Los miembros de la masonería zacatecana buscaron conformar ciudadanos para que, al igual que ellos generaran opinión pública, la cual no necesariamente era afín a la política gubernamental. Los masones como parte de la sociedad civil de la ciudad de Zacatecas llegaron a disentir, proponer y actuar públicamente para llevar a cabo su agenda social-cultural. ¿Por qué opinaban y comentaban sobre cuestiones públicas los masones? ¿Cómo difundían sus argumentos a la sociedad? ¿Cuáles eran sus temas de interés? ¿Con qué sectores discrepaban y por qué?

El tema de la educación fue aludido con recurrencia en las sesiones de los masones, cada integrante manifestaba sus inquietudes, sin embargo, el tema de discusión, generalmente se mantuvo en torno a la intromisión de la Iglesia católica en la formación de ámbitos que los masones consideraban de importancia como los populares, las juventudes e infantes. Su ideal educativo consistió en la formación de personas apegada a lo establecido en la Constitución:

López de Nava pasa a leer su trazado el cual expresa que las corporaciones religiosas, y los ministros de cultos, así como las sociedades pro acciones, que realizan actividades educativas, no intervengan en forma alguna en los planteles en que se imparte la educación secundaria y normal, así como la destinada a obreros y campesinos [...] La veneratura y el querido hermano Ambriz, son los que con sus elocuentes palabras dan sus opiniones al respecto, diciendo que tan solo es el Estado, el que tiene la culpa, de que no se cumpla al pie de la letra, con el art. $3^{\circ}$ de nuestra constitución ${ }^{21}$.

Los masones se pronunciaron a favor de los libros de texto gratuitos y la educación pública laica, manifestando inconformidad ante el gobierno cuando no hacía respetar su monopolio

20 Sánchez Murillo, Breve reseña histórica de las Logias juridisccionadas a la M: R: G: L: del Estado de Zacatecas "Jesús González Ortega" (presentado en el XXV Aniversario de la M:. R:. G.. L:. del Estado de Zacatecas "Jesús González Ortega", s. e., Zacatecas), 13.

21 Archivo de la Gran Logia del Estado de Zacatecas (AHGLEZ), RLS Úrsulo A. García, acta de sesión, julio 22 de 1965, f. 51. 
formativo, no solo en el plano escolar, sino en el cívico y familiar. La Iglesia católica mediante sus comités parroquiales promovió labores de alfabetización, higiene, formación cívica y técnicas agrícolas, mientras que con asociaciones como el Movimiento Familiar Cristiano ${ }^{22}$ realizaron campañas de instrucción a madres y padres de familia, acción que según el masón Bermúdez Ortiz solo el gobierno debía hacer²3.

Fueron estos los motivos por los cuales los integrantes de la logia optaron por realizar el estudio analítico sobre la educación en México, además de declararse defensores de la educación laica y gratuita, denunciando arbitrariedades en la materia y en caso de ser necesario, informar a la Gran Logia del Valle de México requiriendo su apoyo ${ }^{24}$ para poner un alto a esas intromisiones.

El ideal del modelo educativo por el que pugnaban las personas que coincidían en la logia de Zacatecas era entendido como un derecho fundamentado en "el pensamiento revolucionario", por tanto iba de la mano con el progreso, la justicia, el humanismo y el engrandecimiento de la patria, principalmente dirigido a los sectores populares y las juventudes bajo un paradigma nacionalista ${ }^{25}$. Los textos, los comentarios y los actos públicos de los integrantes de la logia, iban en ese tenor, la formación de una ciudadanía nacional acorde al pensamiento liberal, motivo por el cual fundamentaron su oposición a la educación privada, principalmente a la realizada por colegios católicos, así como al gobierno cuando su implicación no era afín a las "verdaderas" causas revolucionarias.

La ambivalencia en el tema educativo en Zacatecas, respecto a la facultad gubernamental, fue constante; ahora bien, cuando la administración estatal era cercana a sus ideales, su intromisión era válida y apoyada, pero si era lo contrario, era cuestionada. Abel Dávila, quien en el mundo profano se dedicó a la docencia en la Universidad Autónoma de Zacatecas ${ }^{26}$, fue opositor de la propuesta de convertir el Instituto de Ciencias Autónomo de Zacatecas en Universidad, debido a las intromisiones del gobernador José Isabel Rodríguez Elías, quien no era de la simpatía de los masones por sus afinidades con el catolicismo ${ }^{27}$. Sin embargo, se apostaba a que su relevo, Pedro Ruiz González, "masón de vanguardia”, pugnara por una restructuración de la política, en la que la universitaria tuviera cabida ${ }^{28}$, por lo que el tema de autonomía universitaria no era asunto primordial para los masones si el modelo educativo era encausado por un gobierno cercano a la asociación.

22 La Voz Diocesana. Órgano oficial de la Junta Diocesana de A.C.M. de Zacatecas, Zacatecas, Zac., Acción Católica, enero 1954, 2-3.

23 AHGLEZ, RLS Úrsulo A. García, acta de sesión, agosto 28 de 1969, ff. 54-56.

24 En tenida ordinaria se informó a la RLS Úrsulo A. García de acciones contrarias al artículo $3^{\circ}$ constitucional, realizadas por el alcalde de Concepción del Oro, Zac., y la Junta Parroquial del mismo lugar, decidiendo informar a la Gran Logia del Valle de México sobre la situación. AHGLEZ, RLS Úrsulo A. García, acta de sesión, julio 25 de 1963, f. 41.

25 Archivo Histórico del Municipio de Zacatecas (AHMZ), Carta de Zacatecas, Col. Dr. José Enciso Contreras, Serie: Masonería. Gran Logia Jesús González Ortega, abril 1962, 5-9.

26 Abel Dávila García nació el 24 de octubre de 1946 y falleció el 25 de junio de 2003. Estudio derecho en el Instituto de Ciencias de Zacatecas y fue profesor del Instituto Tecnológico de Zacatecas y de la Universidad Autónoma de Zacatecas. Autor de: Palabra en la red, Derecho de la Seguridad Social y colaborador de Enciclopedia de los municipios en México. José Enciso Contreras, Diccionario biográfico universitario de Zacatecas (siglos XVIII-XXI) (Zacatecas: Universidad Autónoma de Zacatecas, 2010), 100. En tenida ordinaria de 1964, Rafael Medina Ordaz, manifiesta que "aunque se dialogue con el gobernador, él no dejará de verse en compañía de sacerdotes". AHGLEZ, RLS Úrsulo A. García, acta de sesión, 02 de julio 1964., ff. 122-123. AHGLEZ, RLS Úrsulo A. García, acta de sesión, agosto 15 de 1968, ff. 137-138. 
Otro tema público de discusión por parte de los integrantes de la Úrsulo A. García y que ligaba su interés por el desarrollo de las juventudes con la educación de carácter liberal, fue el movimiento estudiantil de 1968 llevado a cabo en la Ciudad de México. El acontecimiento no significó en la inmediatez para las juventudes de la ciudad de Zacatecas, pero en los masones provocó opiniones, interpretaciones y atención hacia ese sector al considerar a las juventudes el siguiente eslabón del proyecto nacional iniciado a principios del siglo XX. "Tendida está la mano, juventud de México, para que sumes tu fuerza a la continuidad de la obra. El verdadero medio de honrar a la Revolución, es continuarla, llevados del propósito de defender sus postulados" 29 . Sin embargo, se encontraban ante la influencia católica o ideales "extranjeros y extremistas" que aprovechaban de la rebeldía juvenil para desorientarlos de sus fines patrios.

Abel Dávila sostenía que detrás del movimiento estudiantil de 1968 se encontraba el comunismo soviético, al cual calificaba como un "sistema deshumanizador" que alejaba a los jóvenes mexicanos del socialismo humanista y por tal motivo debían estar con ellos, para apoyar y orientar. Algunos estuvieron de acuerdo con su planteamiento, mientras que otros consideraron que la actitud de los jóvenes era consecuencia de su precoz intervención pública y que el Estado debía garantizar la paz, pero no la violencia ${ }^{30}$. El interés manifestado por los masones hacia las juventudes, específicamente en su formación, fue lo que los motivó a investigar sobre su inclusión a la institución, así como a las mujeres, quienes eran persuadidas por las asociaciones y movimientos católicos.

La familia fue considerada por los masones de la ciudad de Zacatecas como la primera esfera de formación libre de vicios y de dogmas, persistiendo, en ciertos casos, con el ideal de solidaridades antiguas, aunque con cierto enfoque moderno mediante la secularización. En el caso de las juventudes se optó por analizar la instalación de una logia AJEF (Asociación de Jóvenes Esperanza de la Fraternidad), el primero en proponerlo fue Jacob Ávila, considerando a los asistentes de la Casa de la Juventud de la ciudad, así como a los hijos de masones. La propuesta AJEF no solo se estableció en el ámbito local, incluso fue parte del plan de trabajo del candidato a la veneratura de la Gran Logia del Valle México, Roberto García Fortoul ${ }^{31}$.

Por otra parte, el interés respecto a la participación de la mujer en la masonería fue iniciativa de Ecliserio Jara, quien en varias sesiones presentó trabajos sobre el tema e incentivó el diálogo. Algunos manifestaron simpatía y disposición para investigar, como Ignacio López de Nava y Rafael Medina; mientras que otros refirieron al ritual escocés, sus costumbres y prohibiciones. Finalmente, optaron por enviar una ponencia a la Gran Logia del Valle de México aludiendo a la participación de la mujer en la masonería ${ }^{32}$. Ahora va a preguntar ¿con qué finalidad se cuestionaba la relación de la mujer con las logias? Los masones asociaban implícitamente a la mujer con la maternidad, entendida por ellos como base de la formación moral de las juventudes, por tal motivo, debían mantener a la mujer fuera de las orientaciones católicas y cerca de la instrucción liberal ${ }^{33}$. Otro elemento que despertó preocupación a los masones

29 AHMZ, Carta de Zacatecas, Col. Dr. José Enciso Contreras, Serie: Masonería. Gran Logia Jesús González Ortega, abril 1962, 9. 30 AHGLEZ, RLS Úrsulo A. García, acta de sesión, agosto 08 de 1968, ff. 135-136.

31 AHGLEZ, RLS Úrsulo A. García, acta de sesión, octubre 10 de 1963, ff. 60-61, acta de sesión informal, noviembre 20 de 1964, f. 4.

32 AHGLEZ, RLS Úrsulo A. García, acta de sesión, abril 2 de 1964, julio 02 de 1964, marzo 04 de 1965, septiembre 19 de 1968.

33 En tenida ordinaria de 1969, Miguel Elías felicita el trabajo de Rodríguez Muñoz, sobre la nueva orientación católica, por referir a las mujeres. A razón de ello propone erigir un monumento a la madre. AHGLEZ, RLS Úrsulo A. García, acta de sesión, mayo 
respecto a la aproximación de la Iglesia hacia las mujeres, fue la desconfianza de los principios morales con que se establecía la relación.

\section{Los masones y la opinión pública}

Desde 1960 analizaron la posibilidad de contar con un periódico mensual, nueve años después conformaron el comité editorial del periódico El Zacatecano integrado por Ignacio López de Nava, como director; Juan F. Acosta, subdirector; Antonio Luna Aguilar, jefe de redacción, y Abel Dávila García, en circulación. El contenido de la publicación fue de carácter cultural, analizando y opinando sin referir a la masonería sobre temas de su acontecer. La circulación del periódico no fue constante debido a la inversión que representaba la impresión. Un año después de la conformación editorial de El Zacatecano, se optó por restructurar el consejo, quedando: Daniel Dávila, como director; Antonio Luna y Raúl López, jefes de redacción; Jesús Vargas, Ecliserio Jara y Rodríguez Muñoz, en la distribución. A manera de propuesta, Abel Dávila sugiere cambiar el nombre del periódico para su nueva etapa y por voto mayoritario eligieron llamarlo Oriente, el cual empezó su circulación en la ciudad a mediados de $1971^{34}$.

Los artículos impresos en El Zacatecano y Oriente cuestionaban políticas públicas, señalando lo que consideraban incorrecto y proponiendo soluciones viables desde su conocimiento. El tema de la educación, al igual que en las tenidas, fue abordado en los periódicos. Entre los cuestionamientos se aludió a programas educativos que incumplían el artículo $3{ }^{\circ}$ constitucional, la crítica refería al permiso obtenido por el clero para contar con instituciones de formación primaria y secundaria, así como escuelas normales, situación que daba pie a la falta de formación íntegra de los docentes ${ }^{35}$. Dentro del mismo ámbito, también se discutía cómo el programa educativo paulatinamente iba alejando a las juventudes de las bibliotecas y de una formación más enfocada en el conocimiento, priorizando la recreación con talleres de cultura física, propiciando manifestaciones inciviles por parte del estudiantado si no se reforzaba su instrucción con actividades culturales que fortalecieran el espíritu humano y científico ${ }^{36}$.

Los contenidos plasmados en los periódicos indican la finalidad del quehacer de los masones en su investidura ciudadana y cómo justificaban su acción en el espacio público. Entre sus objetivos se encontraban la formación del ciudadano ideal, el fomento de una cultura nacional y la generación de opinión pública. Las primeras dos acciones fueron entendidas como de incumbencia estatal en colaboración con el ciudadano modelo, con la finalidad de civilizar para no caer en la barbarie y ciudadanizar para evitar la inmoralidad, la perversión, los viciosos, así como impulsar la colaboración con su ciudad, su sociedad y su patria. Establecieron las formas correctas de actuar en las áreas comunes, pues en su visión, el buen ciudadano no solo es el que participa en las elecciones, el integrante de organismos políticos o asistente a

\footnotetext{
08 de 1969 , ff. 34-35.

34 AHGLEZ, RLS Úrsulo A. García, acta de sesión, septiembre 01 de 1960, junio19 de 1969, julio 21 de 1970, julio 23 de 1970, mayo 06 de 1971, junio 17 de 1971.

35 Murillo Belmonte, Francisco, "La educación secundaria y su expansión”, El Zacatecano, Zacatecas, Zac., año 1, nos. 3 y 4 , septiembre-octubre 1970, 1-5.

36 Medina Ordaz, Rafael, "Psicología de la curiosidad”, El Zacatecano, Zacatecas, Zac., año 1, nos. 3 y 4, septiembre-octubre 1970,
} 6. 
conmemoraciones cívicas, sino es el que con su ejemplo fomenta el civismo en la sociedad y en su familia ${ }^{37}$.

Respecto al fomento de una cultura nacional, la idea del buen ciudadano se localizaba en la exposición de amor a la patria, inculcando a las juventudes respeto por los héroes y símbolos nacionales. De igual forma, los textos escritos por los masones cuestionaban la intromisión cultural que realizaba Estados Unidos en México, manipulando tendenciosamente a la sociedad, influenciándola a actuar contra la moral del ciudadano modelo mexicano $0^{38}$.

Los masones consideraban importante expresar su opinión sobre los acontecimientos de índole público, pues tenían una visión de sí mismos como ciudadanos calificados para incidir. Desde su interpretación, la opinión pública era generada mediante el ejercicio razonado y reflexivo de las personas más calificadas intelectualmente para guiar a las masas, como había sucedido, desde su interpretación de la historia oficial, en los acotamientos históricos de la nación mexicana ${ }^{39}$. Sin embargo, algunos de ellos consideraban que la opinión pública en México se encontraba ausente de crítica constructiva, ante los aplausos, las alabanzas y comentarios superfluos que no visibilizaban los problemas de fondo ${ }^{40}$.

\section{Fines públicos de los masones y su modelo de sociedad civil}

Luego de referir a las formas en que los masones de Zacatecas buscaron participar efectivamente en la sociedad, es posible identificar su finalidad pública, la cual consistió en civilizar, ciudadanizar, moralizar y secularizar el entorno público y privado mediante instituciones de origen societario y sus mecanismos de persuasión como la educación de corte liberal impartida por el Estado, la familia y asociaciones ciudadanas "modernas", así como la generación de opinión pública que cuestionara o redefiniera el camino de la sociedad y de la construcción de su ciudadano modelo. Sin embargo, ¿es posible identificar en su manifestación activa o simbólica un ideal de sociedad civil? En caso de ser así, por sus características societarias ¿cómo puede ser definida la sociedad civil conformada por masones y demás integrantes de asociaciones civiles?

El concepto sociedad civil definido para el estudio, refiere al espacio, esfera o institución social donde interactúan individualidades que voluntariamente forman una organización ciudadana formal o informal, sociabilizan, intercambian puntos de vista, opinan sobre situaciones de incumbencia común y en virtud de su capacidad, buscan incidir en el espacio público como ciudadanos, no como políticos profesionales, comerciantes, empresarios o trabajadores.

Como fue posible observar en las actividades de los integrantes de la Úrsulo A. García, tanto en el taller, como en lo profano, sus reuniones no solo se enfocaron en intercambiar conocimientos esotéricos y dar lectura a textos masónicos, sino de manera consensuada dieron

\footnotetext{
37 "El imperativo del civismo", El Zacatecano, Zacatecas, Zac., año 1, no. 6, enero 1971, 3-4.

38 Arturo García Escobedo, "Penetración de EE.UU. En México", El Zacatecano 1, nos. 3 y 4 (septiembre-octubre 1970 ): 11 y 13. Francisco Murillo Belmonte, Francisco, "La opinión pública", El Zacatecano 1, no. 6 (enero 1971): 1 y 5.

Ignacio López de Nava, "La libertad de prensa", en AHMZ, col. Dr. José Enciso Contreras, serie: Masonería. Gran Logia Jesús González Ortega, exp. 164, colaboración para el Oriente, diciembre 1971, 1-2.
} 
forma a una postura social fuera de la logia, construyeron una asociación ciudadana con una agenda sobre cuestiones públicas que les permitía identificarse como un club de amigos.

Entre los quehaceres más notables estuvo la generación de opinión pública, característica del ciudadano moderno que mediante un ejercicio razonado e individual se manifiesta consciente de la responsabilidad que tiene su argumento. Asimismo, la opinión pública va configurando diversos grupos a partir de la simpatía que provoca, cambiando el ideal social tradicional homogéneo, por uno diverso, libre, que fomenta el razonamiento personal, la esfera privada y la sociedad civil, que en teoría es consecuencia del pensamiento liberal, modificando la visión societaria a partir de individuos, así la opinión pública invita a un diálogo entre emisor y receptor.

En el caso de la opinión realizada por los masones se identifica una conciencia individual por parte del autor, pero la generación de opinión por la que se pronunciaron iba más encaminada a fortalecer la idea de una sociedad homogénea que a incentivar la reflexión personal, en palabras de Francisco Murillo Belmonte y su texto La opinión pública ${ }^{41}$, "la generación de opinión debía guiar a las multitudes”.

La propuesta de Habermas respecto a la formación de sociabilidades, que son asociaciones informales de la sociedad civil a partir de la opinión razonada de individuos, dificulta explicar la realidad donde persisten cosmovisiones comunitarias y corporativas. Sin embargo, el concepto de "esfera pública hibrida", en la cual se combinan las relaciones holistas e individuales, posibilita pensar en una asociación ciudadana y con ello en una "sociedad civil híbrida" que vincule características tradicionales con modernas. Así, las manifestaciones sociales que mezclan ideales societarios comunitarios y personales, como la generación de opinión pública por un autor con el fin de persuadir a un cuerpo social, permiten describir y analizar nuestro objeto de estudio ${ }^{42}$.

Como se mencionó, la idea de sociedad civil se concibe en sociedades modernas, donde la individualidad, consecuencia del liberalismo, es la base del modelo societario; no obstante, para el caso latinoamericano el pensamiento liberal no desvinculó las solidaridades tradicionales, por tanto, no se desarrolló la idea del "sujeto" en su totalidad, situación que fue aprovechada para la constitución de un sistema social y político caciquil que permaneció vigente en el México posrevolucionario ${ }^{43}$. De esta forma, la sociedad civil moderna en Latinoamérica es una minoría, pero la sociedad civil híbrida puede aportar otras formas de analizar nuestro objeto de estudio.

¿Qué características posee la sociedad civil híbrida? ¿Qué factores históricos y sociales posibilitan su conformación? Como se ha explicado, el proceso histórico de las sociedades condiciona el ideal societario; en entidades donde persisten los vínculos tradicionales y una cosmovisión social corporativa, a través de parentescos, el pueblo, la comunidad, gremios y

\footnotetext{
$41 \quad$ Murillo Belmonte, "La opinión", 5.

42 Andrade Guevara, "Xalapa", 211-224.

43 Marialba Pastor, Cuerpos sociales, cuerpos sacrificiales (México DF: Fondo de Cultura Económica, UNAM, 2004), $278-279$.
} 
que con las influencias de la individualidad liberal, se compaginan para configurar la sociedad civil híbrida, la cual combina la interacción entre sujetos que se conciben como ciudadanos y cuerpos sociales para fomentar el espíritu público, una cultura cívica, alcanzar objetivos comunes, mecanismos de cooperación, responsabilidad y solidaridad para solucionar problemas públicos mediante la acción colectiva. En el caso italiano, donde persisten fuertes tradiciones comunitarias, se le denominó a este fenómeno como capital social ${ }^{44}$; por tanto, la sociedad civil híbrida es más la manifestación pública del capital social, conformado a partir de los siguientes elementos: asociacitivismo, generación de relaciones de confianza y propagación de una cultura cívica y cohesión social ${ }^{45}$.

Respecto a la asociación, en nuestro estudio los grupos fueron conformados por iniciativa propia y bajo la investidura ciudadana; por tanto, se refiere a un asociacitivismo civil que en el espacio público trató de influenciar cívica, ideológica y moralmente a otros organismos sociales de características tradicionales, o híbridos. Entre las circunstancias que propician el asociacitivismo, se localizan las herencias sociales, como parentescos y una economía condicionada y dependiente del Estado.

En el caso del capital social, el asociacitivismo es un mecanismo de protección y representación social. Las asociaciones civiles conformadas en la ciudad de Zacatecas buscaban fomentar mecanismos de protección ante cualquier manifestación ideológica extranjera que rompiera con la armonía y la moral posrevolucionaria.

Los integrantes de la Úrsulo A. García apostaron por la educación pública y la familiar, para evitar la incursión de modelos sociales que amenazaban la paz, el progreso y que eran ajenos al prototipo cívico posrevolucionario nacionalista. En ese contexto de inseguridad ideológica consideraron la solución en la instrucción cívica, específicamente en las juventudes, en quienes buscaron depositar su confianza para que continuaran con el proceso nacional en el que ellos creían.

Es precisamente en la instrucción cívica que se localiza el tercer elemento que genera el capital social. En los países que se consideran democráticos por su sistema de representación electoral, el concepto de cultura cívica es entendido como el respeto a las normas de convivencia social. Los integrantes de la logia Úrsulo A. García consideraron la familia y la escuela como los espacios de formación de las normas correctas de convivencia social, de ahí la importancia que le dieron a su orientación.

La sociedad civil híbrida de la ciudad de Zacatecas, representada por la asociación masónica, fue consecuencia de un sistema político que condicionó la organización social, al igual que el proceso histórico societario; sin embargo, debe quedar claro que el Estado posrevolucionario no poseía el monopolio de acción y manifestación social, pues la sociedad civil híbrida, que es la participación activa del capital social, fue un actor autónomo y mediador entre el Estado, la individualidad y la sociedad en su conjunto.

\footnotetext{
$44 \quad$ Aguilar Rivera, En pos, 32-33.

45 Hevia Jara de la, "Capital social”, 165-213.
} 
REHMLAC+, ISSN 2215-6097, vol. 12, nos. 1-2, julio 2020 / diciembre 2020

\section{Fuentes}

\section{Archivos}

Archivo de la Gran Logia del Estado de Zacatecas (AHGLEZ)

Acta de sesión 2da cámara, 25 octubre 1957, Zacatecas, Zac.

Actas de sesión 1959: 29 de mayo.

Actas de sesión 1959: 12 de marzo; o7 y 17 de septiembre; o8 y 11 de octubre;

Actas de sesión 1960: o1 de septiembre; 03 y 10 de noviembre.

Actas de sesión 1961: 19 de octubre; 17 de diciembre.

Actas de sesión 1962: 05 de abril; o2 de agosto; o8, 22 y 29 de noviembre.

Actas de sesión 1963: 28 de marzo; 18 de abril; o6 y 17 de junio; 10 de octubre.

Actas de sesión 1964: 03 y 20 de febrero; 19 de marzo; 02 de abril; 24 de junio; 02 de julio; 22 de octubre; 20 de noviembre.

Actas de sesión 1965: 18 de febrero; 04 y 18 de marzo; 15 de abril; 03 de junio; 2 de julio; 26 de agosto; o2 y 23 de septiembre; 14 de octubre.

Acta de sesión 1966: 24 de febrero.

Actas de sesión 1968: o7 de marzo; 05 de abril; 15 de agosto; 19 de septiembre; 21 de noviembre.

Actas de sesión 1969: o8 de mayo; 19 y 26 de junio; 03 de Julio; 28 de agosto.

Actas de sesión 1970: 21 y 23 de julio; 06 de mayo; 17 de junio.

Archivo Histórico del Municipio de Zacatecas (AHMZ)

AHMZ, Fondo Ayuntamiento II. 1930-1985, Serie; Sindicatos y organizaciones, caja 1, 2, 3 y 4.

AHMZ, col. Dr. José Enciso Contreras, Masonería. Gran Logia Jesús González Ortega, exp. 94, 5-9.

AHMZ, col. Dr. José Enciso Contreras, Masonería. Gran Logia Jesús González Ortega, exp. 125, 1.

AHMZ, col. Dr. José Enciso Contreras, serie: Masonería. Gran Logia Jesús González Ortega, 30 de abril 1964, exp. 115. 


\section{Hemerográficas}

Chicomostoc (Órgano del Club Rotario), 28 de febrero de 1959, Zacatecas, Zac.

Imagen Zacatecas, sección: opinión, Zacatecas, 25 de enero de 2016.

La voz diocesana. Órgano oficial de la funta Diocesana de A.C.M. de Zacatecas, enero 1954, Zacatecas, Zac.

Provincia, 04 de mayo de 1956; 11 y 18 de agosto de 1956; 27 de abril 1957; 11 de mayo de 1957; o1 de junio de 1957; 07, 21 y 28 de septiembre 1957; 02 de noviembre 1957, Zacatecas, Zac.

Sol de Zacatecas, 17 enero de 1957; 24 y 29 de noviembre 1957; 07, 08, o9 y 16 de diciembre 1957; 17 de enero de 1958; 01, 03, 12 y 24 de enero de 1959, Zacatecas, Zac.

Suave Patria (Órgano del Club Rotario), 30 de abril de 1955, Jerez de García Salinas, Zacatecas.

Vox Populi, 19 de agosto de 1948, Zacatecas, Zac.

Voz del Pueblo, 14 y 16 de enero 1958; 27 de febrero 1958; 17 y 29 de julio 1958; 21 de agosto de 1958; o2 de octubre 1958; 17 y 27 de noviembre de 1958; 03, 10, 17, 24 y 26 de enero 1960; 10 de marzo de 1960; 31 de julio de 1960; 25 de agosto de 1960; 10 de noviembre de 1960; 4 de enero de 1962; 18 de marzo de 1962; 21 de octubre de 1962; 22 de noviembre de 1962, Zacatecas, Zac.

Zacatecano, El, enero de 1971, año 1, no. 6, Zacatecas, Zac.

\section{Bibliografía}

Aguilar Rivera, José Antonio. En pos de la quimera. Reflexiones sobre el experimento constitucional atlántico. México DF: Fondo de Cultura Económica, 2000.

Aguilar Valenzuela, Rubén. "Las organizaciones de la sociedad civil en México: su evolución y principales retos". Tesis de doctorado en ciencias sociales, Universidad Iberoamericana, 2006.

Andrade Guevara, Víctor Manuel. "Xalapa: la formación de la esfera pública en el siglo XIX”. Ulúa. Revista de Historia, sociedad y cultura 26 (julio-diciembre 2015).

Bizberg, Ilán. "Una democracia vacía. Sociedad civil, movimientos sociales y democracia". En Los grandes problemas de México. Movimientos sociales. Coordinado por Ilán Bizberg y Francisco Zapata. México DF: El Colegio de México, 2010.

Brachet-Márquez, Vivian. El pacto de dominación. Estado, clase y reforma social en México (1910-1995). México DF: El Colegio de México, 1996. 
Enciso Contreras, José. Diccionario biográfico universitario de Zacatecas (siglos XVIII-XXI). Zacatecas: Universidad Autónoma de Zacatecas, 2010.

Flores, Ángela Dianalthé. “La masonería en el Estado de Zacatecas”. Digesto documental de Zacatecas IV, no. 7 (2006).

García Hernández, Manuel. "Los partidos políticos de izquierda en Zacatecas en la década de los ochenta”. Memorias. Primer informe de investigación sobre el Estado de Zacatecas. Tesis de maestría en ciencia política, 1989.

Hevia, Jara de la, Felipe y Alberto J. Olvera Rivera. "Capital social en el estado de Veracruz". En Violencia, inseguridad y justicia en Veracruz. Coordinado por en Alberto J. Olvera Rivera. Xalapa: Universidad Veracruzana, 2015.

Medina Peña, Luis. La invención del sistema político mexicano. Forma de gobierno y de gobernabilidad en México en el siglo XIX. México DF: Fondo de Cultura Económica, 2004.

Olvera Rivera, Alberto J. coord. La sociedad civil: de la teoría a la realidad. México DF: El Colegio de México, 1999.

Olvera Rivera, J. Alberto. “Democracia y sociedad civil en México: lecciones y tareas”. Comercio exterior 52, no. 5 (Mayo 2002).

Pastor, Marialba. Cuerpos sociales, cuerpos sacrificiales. México DF: Fondo de Cultura Económica, UNAM, 2004.

Sánchez Murillo, Vicente. Breve reseña histórica de las Logias juridisccionadas a la M: R: G: L: del Estado de Zacatecas "Jesús González Ortega”. Presentado en el XXV Aniversario de la M:. R:. G:. L.: del Estado de Zacatecas "Jesús González Ortega”, s. e., Zacatecas.

Sánchez Murillo, Vicente. Breve reseña histórica, texto escrito para presentarse a los integrantes de la Logia "Benito fuárez" no. 2, de la ciudad de Zacatecas, Zac. Zacatecas, equinoccio de otoño de 2011.

Silva-Herzog Márquez, Jesús. El antiguo régimen y la transición en México. México DF: Planeta/Joaquín Mortiz, 1999.

Somuano, María Fernanda. "Las Organizaciones civiles: formación y cambio”. En Los grandes problemas de México. Instituciones y procesos políticos. Coordinado por Soledad Loaeza y Jean-François Prud'homme. México DF: El Colegio de México, 2010. 